\title{
A Mouse Model of Conduction System Patterning Abnormalities in Heterotaxy Syndrome
}

\author{
RICHARD J. CZOSEK, ALLISON HAANING, AND STEPHANIE M. WARE \\ Department of Pediatrics, Cincinnati Children's Hospital Medical Center, University of Cincinnati College of Medicine, \\ Cincinnati, Ohio 45229
}

\begin{abstract}
Duplication or absence of parts of the specialized cardiac conduction system in patients with heterotaxy syndrome causes significant clinical disease, but the mechanistic basis by which embryonic disruption of left-right patterning alters conduction system patterning in these patients is not well understood. We sought to determine whether a mouse model of X-linked human heterotaxy recapitulates conduction system abnormalities identified in patients with heterotaxy. Cardiac structure and conduction system patterning were evaluated in Zic3 null embryos from e9.5 to e16.5 using genetic and molecular methods. Severe structural abnormalities involving atrial, ventricular, and conotruncal development were associated with a spectrum of disorganized and ambiguous arrangements throughout the conduction system, including the appearance of duplicated structures. The severity and location of conduction system abnormalities correlated with the severity and location of associated structural heart disease and were identifiable at the earliest stages examined. The Zic3 mouse model provides a novel tool to dissect the mechanistic underpinnings of conduction system patterning and dysfunction and its relationship to cardiovascular malformations, making it a promising model to improve understanding and risk assessment in the clinical arena. (Pediatr Res 68: 275-280, 2010)
\end{abstract}

$\mathrm{H}^{\mathrm{e}}$ eterotaxy syndrome is characterized by multiple congenital anomalies arising from defects in embryonic leftright patterning and loss of normal asymmetric laterality (1-3). The developing heart is particularly sensitive to leftright positional information, and abnormalities are associated with significant morbidity and mortality because of structural defects and/or arrhythmias (4). Patients with heterotaxy are often described as being "bilateral left-sided" (left isomerism) or "bilateral right-sided" (right isomerism). Cardiac conduction system (CCS) abnormalities in the human heterotaxy population are thought to arise from either duplication or absence of one or more CCS elements resulting from similar left-right patterning abnormalities. Duplication creates a risk for tachycardias, whereas absence or dysfunction of sinoatrial (SA) or atrioventricular (AV) nodal elements can lead to bradyarrhythmias or heart block (5-7) and may require me-

Received February 16, 2010; accepted June 11, 2010.

Correspondence: Stephanie M. Ware, M.D., Ph.D., Cincinnati Children's Hospital Medical Center, 240 Albert Sabin Way, MLC 7020, Cincinnati, OH 45229. e-mail: Stephanie.ware@cchmc.org

Supported by Grant number RO1 HL088639 [S.M.W.] from National Institutes of Health. chanical pacing (8). Heterotaxy syndrome itself is a risk factor for increased mortality (4).

In normal SA nodal development, the initial electrical pacemaker emerges at the inflow region of the linear heart tube (9) and develops adjacent to the venous sinus as it shifts rightward and is incorporated into the right atrium (10). As the SA node matures, there is increasing spatial restriction within the right atrium. The acute switch from ventricular activation emanating from the AV canal to a site at the ventricular apex at mouse embryonic day 10.5-11.5 (e10.5-e11.5) signals a primitive but functioning AV node and His-Purkinje system (11). Visualization of electrical system development in the mouse has been made possible through the use of several CCS transgenic mouse lines, including the CCS-LacZ and $\min K$ lacZ models (11-15). Functional analysis has been achieved through the use of optical mapping using voltage-sensitive dye. In the CCS-LacZ model, this functional analysis has been correlated with anatomical staining patterns of CCS tissue elements (11). These tools have made possible the study of embryonic conduction system patterning; however, little is known about early embryonic patterning and development of the CCS in heterotaxy syndrome.

In humans, mutations of ZIC3 cause the X-linked form of heterotaxy, the most common known genetic etiology of heterotaxy syndrome (2,3). Zic3 is a zinc finger transcription factor and member of the GLI superfamily, important mediators of hedgehog signaling. Analysis of Zic3 null mice has demonstrated the importance of this gene in structural cardiac patterning (16-18). Although a comprehensive examination of cardiac development is lacking, the cardiac phenotypes identified mimic those seen in the human heterotaxy population (19).

In this study, we sought to describe CCS developmental patterning abnormalities in the Zic3 murine heterotaxy model using CCS-LacZ mice for anatomical visualization. Our results indicate that lack of Zic3 significantly affects normal CCS patterning and demonstrates a spatial correlation between structural and conduction system abnormalities. Importantly, the conduction system defects seen in this model are similar to those described in the human heterotaxy population.

Abbreviations: AV, atrioventricular; CCS, cardiac conduction system; CVM, cardiovascular malformations; SA, sinoatrial 
Ultimately, understanding CCS patterning and its correlation with structural cardiac defects may enhance our ability to develop new treatment strategies and provide risk counseling.

\section{METHODS}

Mouse embryo collection and $\beta$-gal detection. Embryos were collected following timed matings. Zic3 null and control embryos were stage matched for analyses to within $0.5 \mathrm{~d}$ based on somite number (early embryos) or limb bud outgrowth and digit appearance (later embryos). CCS-LacZ embryos were stained with 5-bromo-4-chloro-3-indolyl- $\beta$-D-galactoside (X-Gal) staining solution as described previously (20). CCS-LacZ and Zic3 null/CCS-LacZ embryos were collected at e9.5-e16.5 and fixed in 4\% paraformaldehyde/PBS for $15 \mathrm{~min}$ at $4{ }^{\circ} \mathrm{C}$ and then rinsed in PBS. Embryos were stained with X-Gal solution at room temperature for $48 \mathrm{~h}$ and postfixed in $4 \%$ paraformaldehyde/ PBS for $1 \mathrm{~h}$ at $4^{\circ} \mathrm{C}$. This study was approved by the Cincinnati Children's Hospital Institutional Animal Care and Use Committee.

Preparation of CCS-LacZ sections and photo imaging. Embryos were dehydrated through an increasing gradient of ethanol followed by multiple xylene washes and paraffin embedding. Sections were cut transversely at 12-14 $\mu \mathrm{m}$ using a microtome (Leica Microsystems, Wetzlar, German). Sections were deparaffinized in xylene, counterstained with eosin, dehydrated in xylene, and coverslipped using cytoseal (Electron Microscopy Sciences, Hatfield, PA). Images were captured using a Nikon DXM 1200F digital camera coupled to a Nikon Eclipse E400 microscope (Nikon Instruments Inc., Melville, NY).

Synthesis of digoxigenin-labeled riboprobes. The cDNA sequence corresponding to amino acids 400-690 of mouse Hcn4 (base pairs 1198-2068 of NM_001081192) was amplified from mouse heart RNA with the primers 5'-ATATCTAGACAGTG GGAAGAGATCTTCCA-3' and 5'-ATACTCGAGTGAAGTTGTCCACGCTCAGT-3' and subcloned into the XbaI-XhoI sites of pBluescript II SK(-). This region of $\mathrm{mHcn} 4$ effectively labels specific components of the adult mouse CNS (21) and has been identified as a marker of the SA node. The $m N k x 2-5$ riboprobe plasmid was kindly provided by Dr. Yutzey (22). Antisense riboprobes were generated by in vitro transcription with the appropriate RNA polymerase in the presence of digoxigenin (DIG) RNA labeling mix.

In situ hybridization. In situ hybridization was performed as described previously (23). Paraffin-embedded embryos were sectioned transversely, and 12-14 $\mu \mathrm{m}$ sections were mounted on Superfrost Plus microscope slides (Thermo Fisher Scientific, Waltham, MA). Sections were hybridized with 200 $\mu \mathrm{L}$ of digoxigenin-labeled riboprobe at $1 \mu \mathrm{g} / \mathrm{mL}$ in incubation chambers $(22 \times 40 \times 0.2 \mathrm{~mm}$, Electron Microscopy Sciences, Hatfield, PA). Color development was performed using BM Purple (Roche Applied Science, Indianapolis, IN) for $8-12 \mathrm{~h}$.

\section{RESULTS}

Development of structural cardiac abnormalities in Zic3 null mice. Patients with heterotaxy have a diverse spectrum of cardiovascular malformations (CVMs). To evaluate the cardiac anomalies in a mouse model of heterotaxy, embryos were evaluated from e9.5 to e16.5. Structural cardiac abnormalities decreased at later embryonic stages (40\% of nulls had structurally abnormal hearts at e10.5, 32\% at e11.5, and $25 \%$ at e12.5). A reduction in litter size after e 10.5 was consistent with embryonic lethality caused by complex CVMs. The cardiac phenotypes in Zic3 null embryos were variable and recapitulated the spectrum of phenotypes seen in human heterotaxy syndrome. Gross examination of the hearts at e10.5e12.5 demonstrated a range of phenotypes including univentricular morphology and conotruncal abnormalities (Fig. 1 and data not shown). By e10.5, the normal heart has undergone the initial rightward bending of the linear heart tube (dlooping), and the common outflow tract has looped as a precursor to development of normal great artery relationship. The developing atrial chambers lie posterior to two well-developed ventricular chambers, and the outflow tract

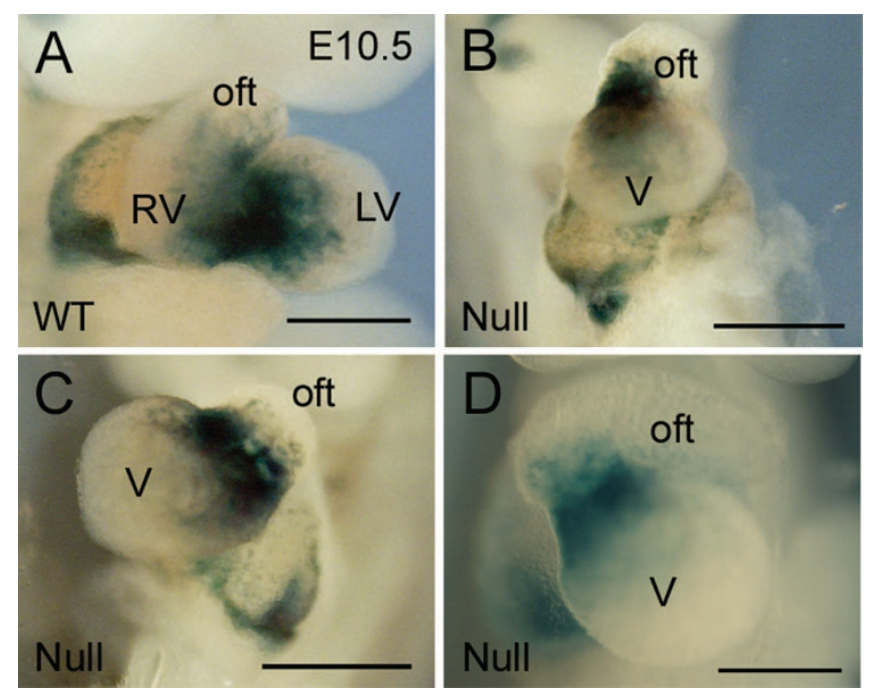

Figure 1. Abnormal cardiac development in Zic3 embryos. A, Wild-type embryo at e10.5 with typical d-looped ventricular configuration. $B$, Zic3 null embryo with primitive ventricular configuration. $C$, Univentricular morphology with 1-looping. The outflow tract arises from the leftward aspect of the ventricular chamber. There is dextrocardia with a rightward ventricular apex. $D$, Univentricular morphology with d-looping. The outflow tract arises from the rightward aspect of the ventricular chamber, and the ventricular apex is directed leftward. X-gal staining illustrates the developing CCS. Scale bars are $300 \mu \mathrm{m}$. oft, outflow tract; $\mathrm{LV}$, left ventricle; $\mathrm{RV}$, right ventricle; $\mathrm{V}$, ventricle.

arises from the right ventricle (Fig. 1A). Figure $1 \mathrm{C} \mathrm{dem-}$ onstrates conotruncal malposition in a Zic3 null embryo, with the common outflow arising vertically and centrally from the most superior aspect of the ventricular chambers. The atria are abnormally positioned inferior to the ventricular chambers. Figure $1 C$ demonstrates l-looped malposition of the outflow tract and inferior displacement of the atria. Although wild-type embryos have two developing ventricles at e10.5, a subset of Zic3 null embryos demonstrate univentricular morphology (Fig. $1 C$ and $D$ ), with a single ventricular chamber giving rise to a single outlet. Conotruncal abnormalities were common and always associated with additional structural abnormalities. The range of defects in cardiac looping observed during cardiac development in these null mice provides insight into the variable phenotypic presentations of patients with heterotaxy.

SA nodal development. CCS development in patients with heterotaxy syndrome has been associated with loss of the normal asymmetric restriction of the SA node within the right atrium. Both inversion of the SA node with a single pacemaker in the left atrium and duplication or "twinning" of the SA node with both right and left atrial intrinsic pacemakers have been described. Genetic and molecular methods were used to investigate SA node development in Zic3 null mice. Mating Zic3 mice with CCS-LacZ mice allowed for visualization of CCS development in Zic3 null embryos based on the staining pattern. Abnormalities in SA nodal development in Zic3 null embryos ranged from apparently normal to severely abnormal. There was strong correlation between the presence of structural defects and abnormal SA node patterning: Zic3 null embryos with normal structural anatomy had normal SA nodal staining patterns, whereas embryos with abnormal structure displayed either normal or abnormal SA nodal patterning. 


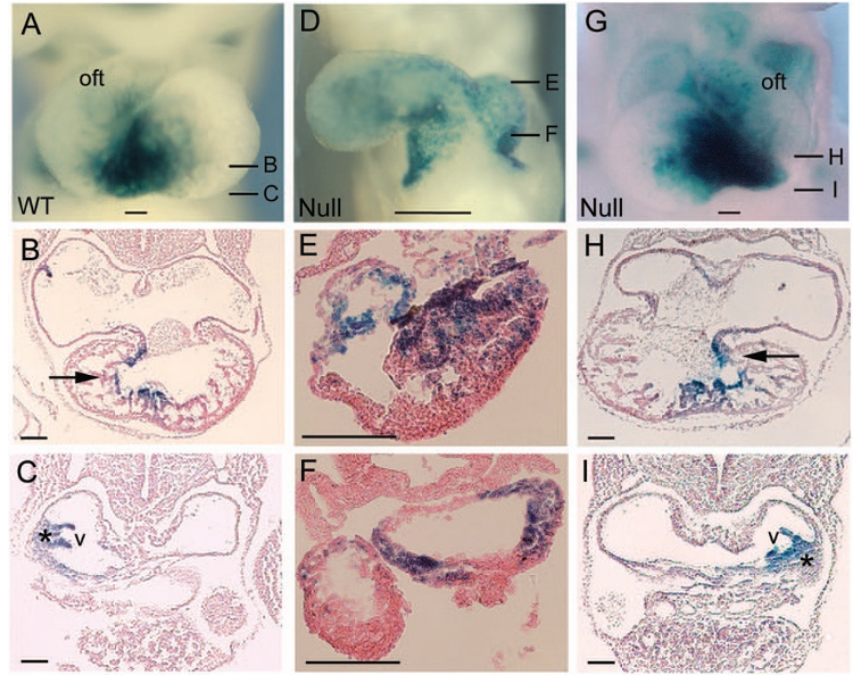

Figure 2. Abnormal cardiac conduction system development in structurally abnormal embryos. Wild-type $(A-C)$ and Zic3 null $(D-I)$ cardiac morphology and conduction system staining at e10.5. A, Wild-type cardiac morphology with typical d-looping. $B$ and $C$, Transverse sections at the levels indicated in (A) demonstrate the distal conduction system is a single linear band positioned rightward within the RV (arrow), and a normal SA nodal staining pattern restricted to the right atrium (*). $D$, Severe cardiac structural abnormalities with univentricular morphology and abnormal bilateralization of atrial staining. $E$ and $F$, Sections at the levels indicated in $(D)$ demonstrate abnormal atrial and ventricular development with conduction system staining in both the left and right aspects of the common atrium. $G$, Mirror image dextrocardia with 1-looped ventricular morphology. $H$ and $I$, Mirror image SA nodal patterning (*) with restriction of staining in the left atrium. The AV node and His bundle are leftward (arrow). Scale bars in $A, D$, and $G$ are $100 \mu \mathrm{m}$. Scale bars in $B, C, E, F, H$, and $I$ are $50 \mu \mathrm{m}$. Oft, outflow track; v, atrial venous valve.

Abnormalities in left-right patterning were identified based on loss of normal SA node lateralization and restriction within the right atrium (Fig. 2). These findings are similar to those found in clinical descriptions of SA nodal development in the human heterotaxy population. Normal SA node staining is restricted to the right atrium and right sinus valve (Fig. $2 A-C$ ), and the pattern of staining is somewhat diffuse at developmental stages younger than e10.5. As development continues, the staining pattern becomes progressively more restricted to the superior right atrium adjacent to the superior vena cava and the venous valve, the general location of the mature SA node. In Zic3 null embryos, two patterns of SA nodal development were seen. Examples of SA node inversus were found, both with SA nodal development restricted to the left atrium and bilateralization of SA node development. Failure of proper lateralization of the SA node indicates ambiguous patterning consistent with right atrial isomerism (Fig. 2D-F). Figure $2 G-I$ demonstrates a left-sided SA node in a null embryo with 1-looping.

SA node development in Zic3 null embryos was evaluated further using molecular methods. Previous studies have elaborated a molecular pathway for localized formation of the SA node (24-26). The atrial myocardium is characterized by expression of myocardial markers such as $N p p a$ and $N k x 2.5$, whereas the nonmyocardial SA node region expresses markers such as the pacemaker channel gene product, Hcn4. During heart tube maturation, Nkx2.5 progressively represses expres-

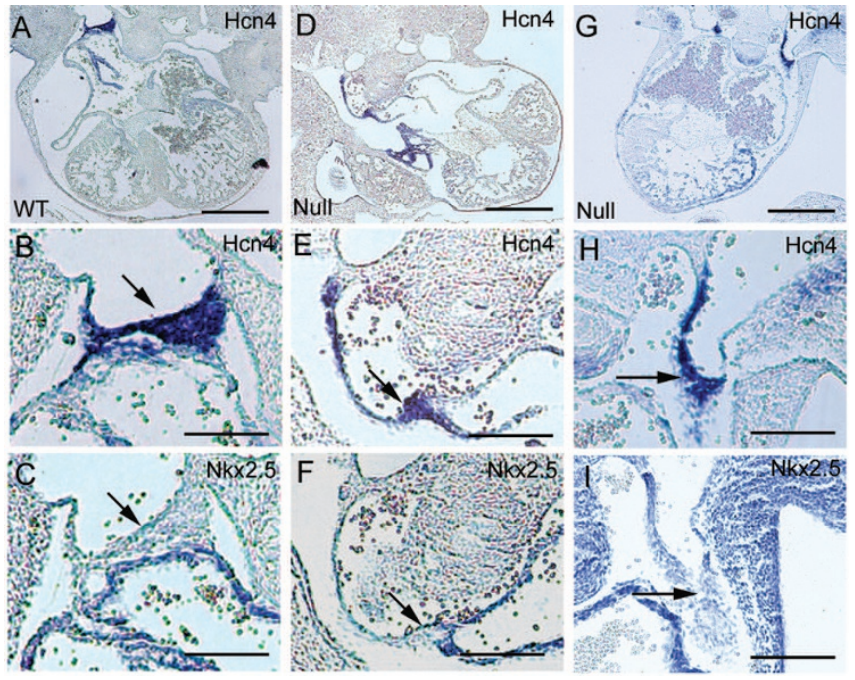

Figure 3. SA node patterning is abnormal in e11.5 Zic3 null embryos. A-C Molecular characterization in a wild-type embryo. In (A), Hcn4 expression delineates the SA node, positioned above the right atrium. $B$, High-power view of SA node visualized in $(A)$, demonstrating Hcn4 staining of a wedge-shaped area of tissue. $N k \times 2.5$ is excluded from this region (arrow) but is expressed in the surrounding myocardium in $(C) . D-F, Z i c 3$ null embryo with abnormal anteroposterior positioning of the ventricles and misalignment of the atria. The abnormally elongated SA node region is indicated by presence of Hcn 4 staining ( $D, E$, arrow) and lack of $N k x 2.5$ staining $(F)$. G-I. Zic3 null embryo with dextrocardia and common ventricle. Strong bilateral $H c n 4$ staining was observed above the atria $(G$ and $H$ ), and $N k x 2.5$ staining was absent $(I)$. Scale bars in $A, D$, and $G$ are $0.5 \mathrm{~mm}$. Scale bars in $B, C, E$, $F, H$, and $I$ are $100 \mu \mathrm{m}$.

sion of Hcn4, resulting in molecular delineation of a distinct, compact SA node region in the right atrium. To determine whether specification of the SA node occurs properly in Zic3 null embryos, the expression of Nkx2.5 and Hcn4 was determined by in situ hybridization. In e11.5 wild-type embryos, the SA node is a triangular wedge of tissue, which is Hcn4 positive and $N k x 2.5$ negative (Fig. $3 A-C$ ). At these stages, $H c n 4$ expression is localized to the same anatomic structures identified by $\mathrm{X}$-gal staining in CCS-LacZ mice but is more spatially restricted in its expression profile. Zic3 null embryos (Fig. 3D-I) retain the mutually exclusive expression pattern of Hcn4 and Nkx2.5 identified in wild-type embryos; however, the positioning and morphology of the SA node tissue are abnormal. There is a diffuse appearance to some SA nodal structures, as well as abnormal shape and positioning (Fig. $3 E$, $F, H$, and $I$ ). The expression pattern in embryos with bilateral staining (Fig. 3G, bilateral SA nodes) tended to be more diffuse and heterogeneous compared with the wild-type patterning. These results imply that Zic3 is not required for SA node specification but plays a central role in proper localization.

Organization of CCS after completion of cardiac looping. By e12.5, the final phases of cardiac looping are complete, and restriction and maturation of CCS patterning occur. In Zic3 null embryos, structural defects are present along with abnormal SA node morphogenesis and abnormal development of the distal conduction system (Fig. 4). SA node development at e12.5 is characterized by further restriction and organization of the staining pattern within the right atrium (Fig. 4). In contrast, SA node tissue in Zic3 null embryos at e12.5 dem- 


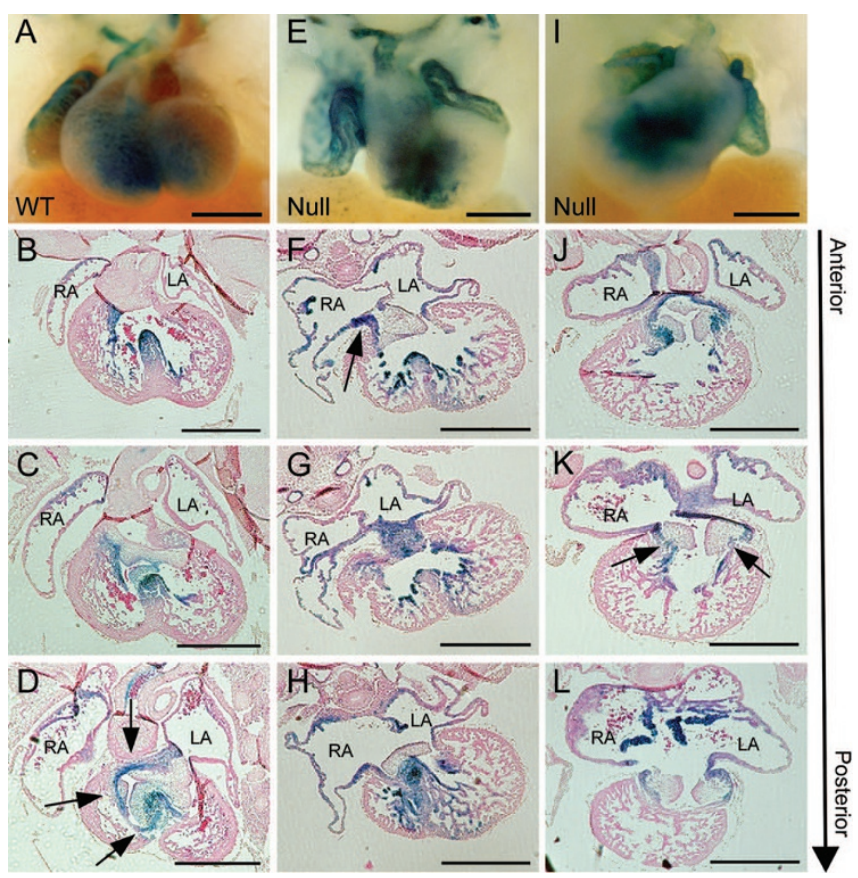

Figure 4. Distal conduction system patterning is abnormal in Zic3 null embryos at e12.5. $A-D$, Normal patterning with a single staining band (arrows) from the crest of the developing interventricular septum to the AV node. E-H, Zic3 null embryo with accessory pathway connection (arrow) separate from the normal tract connecting the bundle branches and AV node. This tract resides lateral to the normal linear band connecting the right ventricular myocardium with the right aspect of the AV valve and right atrium. I-L, Zic3 null embryo with abnormal AV valve septation and positioning relative to the ventricular chambers with retention of the common AV valve and loss of normal septation between the mitral and tricuspid valves. The embryo has a primitive circumferential AV canal staining pattern giving rise to two separate tracts (arrows) from the developing AV node to the ventricular myocardium. Scale bars are $500 \mu \mathrm{m}$. RA, right atrium; LA, left atrium.

onstrates diffuse, disorganized X-gal staining patterns within the atrial chamber, in addition to the bilateralization of the staining (Fig. $4 F, J$, and $K$ ). These results provide evidence of failure to properly pattern the SA node. Additionally, the diffuse and disorganized appearance of SA node staining suggests a possible temporal disruption, with retention of primitive patterning features. Absence of SA nodal staining, suggestive of left atrial isomerism, was also identified (data not shown).

Distal conduction system abnormalities, involving the AV node, His bundle, or Purkinje system, in patients with heterotaxy can result in both abnormal positioning and duplication of CCS elements. "Twinning" or duplication of the AV node in humans may lead to a form of reentry tachycardia. Distal conduction system patterning demonstrated a relationship between structural and CCS patterning defects similar to that observed in more proximal SA nodal development. Again, Zic3 null embryos with normal cardiac structure demonstrated universally normal distal conduction system patterning. In hearts with structural abnormalities, the distal conduction system was abnormal to varying degrees in all embryos analyzed (Table 1). Before e10.5, the entire AV canal functions as AV nodal tissue and the staining pattern is circumferential, encompassing the entire periphery of the AV canal
Table 1. Correlation of structural and CCS patterning abnormalities

\begin{tabular}{|c|c|c|c|c|c|}
\hline Stage & Litters & $\begin{array}{c}\text { Zic3 } \\
\text { null } \\
\text { embryos }\end{array}$ & $\begin{array}{c}\text { Zic3 null } \\
\text { structural } \\
\text { abnormality }\end{array}$ & $\begin{array}{l}\text { Zic3 null } \\
\text { CCS } \\
\text { abnormality }\end{array}$ & $\begin{array}{l}\text { Embryos } \\
\text { sectioned }\end{array}$ \\
\hline e10.5 & 4 & 19 & 10 & 10 & 7 \\
\hline e11.5 & 2 & 7 & 2 & 2 & 2 \\
\hline e12.5 & 9 & 40 & 11 & 11 & 9 \\
\hline e14.5 & 3 & 3 & 0 & 0 & 0 \\
\hline e16.5 & 4 & 4 & 0 & 0 & 2 \\
\hline
\end{tabular}

region. Following a timeline similar to SA node maturation, the AV node becomes restricted to its adult position and initiates compaction and organization by e12.5 (Fig. 4A-D). Distal to the AV node, the compacted CCS continues as a linear band of tissue extending to the distal Purkinje system through the right posterior aspect of the AV canal and right ventricular region (Fig. 4D).

In abnormal Zic3 null embryos, patterning was disrupted at the level of the AV node, His bundle, and bundle branches. Abnormalities of the AV node included disorganization with loss of normal compaction characterized by diffuse staining (Fig. 4G). Rarely, duplication of AV nodal tissue was visualized. His bundle and bundle branch patterning were also significantly affected. The staining around the periphery of the AV canal in Figure 4I-L illustrates the failure to restrict CCS patterning distal to the AV node. The typical single linear band extending from the AV node to the distal Purkinje system is replaced by two tracts. Staining patterns consistent with accessory connections from the atrium and ventricle were also identified in a subset of embryos, possibly indicating future phenotypic accessory pathway development (Fig. $4 F$ and $K$ ). These findings indicate that deficiency of Zic3 can severely affect embryonic patterning of the distal conduction system and imply a strong relationship between abnormalities in cardiac structure and the distal conduction system. Importantly, these abnormalities are similar to those commonly seen in the human heterotaxy population (Table 2).

\section{DISCUSSION}

In humans, heterotaxy syndrome is associated with severe cardiac structural and conduction system abnormalities and is an independent risk factor for postoperative mortality after surgical palliation $(3,5)$. The clinical impact of these conduction system abnormalities has been based on postnatal functional assessment with bradycardia or heart block. Although the molecular cues important for development of conduction system lineage are beginning to be elaborated (24-26), the embryonic events controlling conduction system pattern formation are largely unknown. In this study, we examined conduction system development and its association with structural development in the Zic3 heterotaxy mouse model.

Loss of normal left-right differentiation affects CCS patterning. All structurally abnormal Zic3 null hearts exhibited CCS abnormalities. However, even at these early developmental stages, there were no embryos with completely identical cardiac abnormalities in our series, consistent with the clinical heterogeneity of heterotaxy. In the proximal CCS, SA node 
Table 2. Representative cardiac abnormalities in Zic3 null embryos

\begin{tabular}{|c|c|c|}
\hline Stage & Cardiac structural abnormalities & $\begin{array}{l}\text { Conduction system } \\
\text { abnormalities }\end{array}$ \\
\hline e10.5 & $\begin{array}{l}\text { L-looped ventricles, conotruncal } \\
\text { malposition, and inferiorly } \\
\text { displaced atria }\end{array}$ & $\begin{array}{l}\text { Normal SA nodal patterning } \\
\text { and abnormal distal CCS } \\
\text { patterning }\end{array}$ \\
\hline e10.5 & $\begin{array}{l}\text { L-looped ventricles and } \\
\text { widened conotruncus }\end{array}$ & SA node inversion \\
\hline e10.5 & L-looped ventricles & $\begin{array}{l}\text { Absent SA node and } \\
\text { abnormal distal CCS } \\
\text { patterning }\end{array}$ \\
\hline e10.5 & Univentricular morphology & $\begin{array}{l}\text { Normal SA node patterning } \\
\text { and abnormal distal CCS } \\
\text { patterning }\end{array}$ \\
\hline e11.5 & $\begin{array}{l}\text { Univentricular morphology and } \\
\text { bilateral superior vena cava }\end{array}$ & SA node duplication \\
\hline e12.5 & DORV & $\begin{array}{l}\text { Biatrial SA nodes, duplication } \\
\text { of AV nodal tissue, and } \\
\text { accessory pathway } \\
\text { connection }\end{array}$ \\
\hline e12.5 & DILV & Biatrial SA nodes \\
\hline e12.5 & Situs inversus & Mirror image CCS elements \\
\hline $\mathrm{e} 12.5$ & Univentricular morphology & $\begin{array}{l}\text { Abnormal SA node patterning } \\
\text { and abnormal distal CCS } \\
\text { patterning }\end{array}$ \\
\hline
\end{tabular}

CCS, central conduction system; DORV, double-outlet right ventricle; DILV, double-inlet left ventricle.

duplication was the most common finding (right isomerism, $n=7 / 18$ sectioned embryos). In addition, lack of SA nodal development (left isomerism, $n=4 / 18$ ) and exclusive left atrial staining associated with complete reversal of myocardial and CCS structures (situs inversus, $n=3 / 18$ ) were identified. These abnormalities of duplicated or absent CCS elements mimic those seen in the human heterotaxy population (27-29). Hypoplasia of the SA node has been associated with aberrant lineage specification, as manifest by ectopic expression of $N k x 2.5$, in mouse models such as Shox2 null mice (30). In contrast, Zic3 null mice form a normal boundary of Hcn4 and $N k x 2.5$ expression in the atria, indicating that Zic3 deficiency does not impair lineage specification or the molecular signature of the SA node and will, therefore, be a useful tool to dissect the secondary consequences of abnormal left-right patterning on SA node patterning, structural malformation, and ultimately CCS function.

Clinically, the left atrial isomerism leads to bradyarrhythmias secondary to SA node dysfunction, whereas the right atrial isomerism is associated with sinus propagation alternating between the right- and left-sided intrinsic pacemakers $(8,29)$. Understanding how SA node patterning affects function is therefore clinically relevant. The current studies cannot rule out the possibility that Zic3 null mice with normalappearing staining patterns have inherent functional abnormalities. Future studies assessing functional characteristics by voltage-gated visualization embryonically (11) or intracardiac electrophysiology testing postnatally could help resolve this question (31).

In addition to the SA nodal abnormalities described, Zic3 null embryos also demonstrate abnormal AV nodal patterning. Before e10.5, staining circumferentially around the AV canal appears normal in Zic3 null embryos. After e10.5, AV node abnormalities including disorganization, malpositioning, or mislocalization are identified ( $n=6 / 9 \mathrm{~d} 12.5$ sectioned embryos), similar to abnormalities seen in SA nodal patterning. This pattern is consistent with human pathology studies in which both AV nodal structures are displaced and can be dysfunctional (32). Similar inhibition of distal CCS compaction including alterations in AV node and His-purkinje system disorganization is seen on neural crest ablation (33).

In Zic3 null embryos, there was evidence of additional AV pathways consistent with conventional accessory pathways or Mahaim connections $(n=2 / 9)$, a common finding in patients with heterotaxy syndrome and l-looped ventricular configuration that can result in the typical form of $\mathrm{AV}$ reciprocating tachycardia (34). The CCS-LacZ model has been used previously to describe CCS abnormalities such as Mahaim fiber development and delineation of embryonic cardiac regions with future arrhythmogenic potential $(13,14)$.

Zic3 null mice exhibit mixed morphologies (e.g. right or left isomerism) indicating that they encompass the full range of heterotaxy spectrum defects. Mouse models with exclusive right or left isomeric patterns, such as Pitx2 or Lefty- 1 knockouts, have been described anatomically but have not been analyzed in depth with regard to CCS development $(35,36)$. Clinically, understanding how conduction system patterning correlates with congenital heart disease is important for management.

In summary, proper patterning of the CCS requires a complex interplay of embryonic left-right differentiation. CCS abnormalities in the Zic3 heterotaxy model are closely linked with associated abnormalities of cardiac structure. Loss of Zic3 leads to abnormal CCS structure and maturation that coincides with the severity and location of associated structural heart disease. Potential mechanisms for this disruption include ambiguous patterning, duplication of tissue patterning, and/or failure of progressive development with retention of earlier embryonic patterns. The congruent relationship of structural and CCS patterning abnormalities seem to indicate shared regulatory programs directing developmental patterning, although future lineage studies will be needed to more clearly delineate this relationship. This mouse model provides a novel tool to dissect the genetic regulatory hierarchy linking left-right patterning with conduction system-specific gene expression and pattern formation and elucidation of human rhythm abnormalities.

Acknowledgments. We thank Glenn Fishman for the use of the CCS-LacZ reporter mouse line.

\section{REFERENCES}

1. Ramsdell AF 2005 Left-right asymmetry and congenital cardiac defects: getting to the heart of the matter in vertebrate left-right axis determination. Dev Biol 288:1-20

2. Sutherland MJ, Ware SM 2009 Disorders of left-right asymmetry: heterotaxy and situs inversus. Am J Med Genet C Semin Med Genet 151C:307-317

3. Belmont JW, Mohapatra B, Towbin JA, Ware SM 2004 Molecular genetics of heterotaxy syndromes. Curr Opin Cardiol 19:216-220

4. Jacobs JP, O'Brien SM, Chai PJ, Morell VO, Lindberg HL, Quintessenza JA 2008 Management of 239 patients with hypoplastic left heart syndrome and related malformations from 1993 to 2007. Ann Thorac Surg 85:1691-1696; discussion 1697

5. Wilkinson JL, Smith A, Lincoln C, Anderson RH 1978 Conducting tissues in congenitally corrected transposition with situs inversus. Br Heart J 40:41-48 
6. Cheung YF, Cheng VY, Yung TC, Chau AK 2002 Cardiac rhythm and symptomatic arrhythmia in right atrial isomerism. Am Heart J 144:159-164

7. Epstein MR, Saul JP, Weindling SN, Triedman JK, Walsh EP 2001 Atrioventricular reciprocating tachycardia involving twin atrioventricular nodes in patients with complex congenital heart disease. J Cardiovasc Electrophysiol 12:671-679

8. Wu MH, Wang JK, Lin JL, Lai LP, Lue HC, Hsieh FJ 2001 Cardiac rhythm disturbances in patients with left atrial isomerism. Pacing Clin Electrophysiol 24:1631-1638

9. Gourdie RG, Harris BS, Bond J, Justus C, Hewett KW, O'Brien TX, Thompson RP, Sedmera D 2003 Development of the cardiac pacemaking and conduction system. Birth Defects Res C Embryo Today 69:46-57

10. Moorman AF, de Jong F, Denyn MM, Lamers WH 1998 Development of the cardiac conduction system. Circ Res 82:629-644

11. Rentschler S, Vaidya DM, Tamaddon H, Degenhardt K, Sassoon D, Morley GE, Jalife J, Fishman GI 2001 Visualization and functional characterization of the developing murine cardiac conduction system. Development 128:1785-1792

12. Kondo RP, Anderson RH, Kupershmidt S, Roden DM, Evans SM 2003 Development of the cardiac conduction system as delineated by minK-lacZ. J Cardiovasc Electrophysiol 14:383-391

13. Jongbloed MR, Schalij MJ, Poelmann RE, Blom NA, Fekkes ML, Wang Z, Fishman GI, Gittenberger-De Groot AC 2004 Embryonic conduction tissue: a spatial correlation with adult arrhythmogenic areas. J Cardiovasc Electrophysiol 15:349-355

14. Jongbloed MR, Wijffels MC, Schalij MJ, Blom NA, Poelmann RE, van der Laarse A, Mentink MM, Wang Z, Fishman GI, Gittenberger-de Groot AC 2005 Development of the right ventricular inflow tract and moderator band: a possible morphological and functional explanation for Mahaim tachycardia. Circ Res 96:776-783

15. Myers DC, Fishman GI 2004 Toward an understanding of the genetics of murine cardiac pacemaking and conduction system development. Anat Rec A Discov Mol Cell Evol Biol 280:1018-1021

16. Purandare SM, Ware SM, Kwan KM, Gebbia M, Bassi MT, Deng JM, Vogel H, Behringer RR, Belmont JW, Casey B 2002 A complex syndrome of left-right axis, central nervous system and axial skeleton defects in Zic3 mutant mice. Development 129:2293-2302

17. Ware SM, Harutyunyan KG, Belmont JW 2006 Heart defects in X-linked heterotaxy: evidence for a genetic interaction of Zic3 with the nodal signaling pathway. Dev Dyn 235:1631-1637

18. Ware SM, Harutyunyan KG, Belmont JW 2006 Zic3 is critical for early embryonic patterning during gastrulation. Dev Dyn 235:776-785

19. Ware SM, Peng J, Zhu L, Fernbach S, Colicos S, Casey B, Towbin J, Belmont JW 2004 Identification and functional analysis of ZIC3 mutations in heterotaxy and related congenital heart defects. Am J Hum Genet 74:93-105

20. MacGregor GR, Nolan GP, Fiering S, Roederer M, Herzenberg LA 1991 Use of $E$ Coli lacZ ( $\beta$-Galactosidase) as a reporter gene. In: Murray EJ (ed) Gene Transfer and Expression Protocols. The Humana Press Inc., Clifton, pp 217-235

21. Santoro B, Chen S, Luthi A, Pavlidis P, Shumyatsky GP, Tibbs GR, Siegelbaum SA 2000 Molecular and functional heterogeneity of hyperpolarization-activated pacemaker channels in the mouse CNS. J Neurosci 20:5264-5275
22. Searcy RD, Vincent EB, Liberatore CM, Yutzey KE 1998 A GATA-dependen nkx-2.5 regulatory element activates early cardiac gene expression in transgenic mice. Development 125:4461-4470

23. Shelton EL, Yutzey KE 2007 Tbx20 regulation of endocardial cushion cell proliferation and extracellular matrix gene expression. Dev Biol 302:376-388

24. Hoogaars WM, Engel A, Brons JF, Verkerk AO, de Lange FJ, Wong LY, Bakke ML, Clout DE, Wakker V, Barnett P, Ravesloot JH, Moorman AF, Verheijck EE, Christoffels VM 2007 Tbx3 controls the sinoatrial node gene program and imposes pacemaker function on the atria. Genes Dev 21:1098-1112

25. Hoogaars WM, Tessari A, Moorman AF, de Boer PA, Hagoort J, Soufan AT, Campione M, Christoffels VM 2004 The transcriptional repressor Tbx3 delineates the developing central conduction system of the heart. Cardiovasc Res 62:489-499

26. Mommersteeg MT, Hoogaars WM, Prall OW, de Gier-de Vries C, Wiese C, Clout DE, Papaioannou VE, Brown NA, Harvey RP, Moorman AF, Christoffels VM 2007 Molecular pathway for the localized formation of the sinoatrial node. Circ Res 100:354-362

27. Dickinson DF, Wilkinson JL, Anderson KR, Smith A, Ho SY, Anderson RH 1979 The cardiac conduction system in situs ambiguus. Circulation 59:879-885

28. Ho SY, Seo JW, Brown NA, Cook AC, Fagg NL, Anderson RH 1995 Morphology of the sinus node in human and mouse hearts with isomerism of the atrial appendages. Br Heart J 74:437-442

29. Cohen MS, Anderson RH, Cohen MI, Atz AM, Fogel M, Gruber PJ, Lopez L, Rome JJ, Weinberg PM 2007 Controversies, genetics, diagnostic assessment, and outcomes relating to the heterotaxy syndrome. Cardiol Young 17:29-43

30. Blaschke RJ, Hahurij ND, Kuijper S, Just S, Wisse LJ, Deissler K, Maxelon T, Anastassiadis K, Spitzer J, Hardt SE, Scholer H, Feitsma H, Rottbauer W, Blum M, Meijlink F, Rappold G, Gittenberger-de Groot AC 2007 Targeted mutation reveals essential functions of the homeodomain transcription factor Shox 2 in sinoatrial and pacemaking development. Circulation 115:1830-1838

31. Berul CI, Aronovitz MJ, Wang PJ, Mendelsohn ME 1996 In vivo cardiac electrophysiology studies in the mouse. Circulation 94:2641-2648

32. Bae EJ, Noh CI, Choi JY, Yun YS, Kim WH, Lee JR, Kim YJ 2005 Twin AV node and induced supraventricular tachycardia in Fontan palliation patients. Pacing Clin Electrophysiol 28:126-134

33. Gurjarpadhye A, Hewett KW, Justus C, Wen X, Stadt H, Kirby ML, Sedmera D, Gourdie RG 2007 Cardiac neural crest ablation inhibits compaction and electrical function of conduction system bundles. Am J Physiol Heart Circ Physiol 292:H1291-H1300

34. Bharati S, Lev M 1975 The course of the conduction system in single ventricle with inverted (L-) loop and inverted (L-) transposition. Circulation 51:723-730

35. Meno C, Shimono A, Saijoh Y, Yashiro K, Mochida K, Ohishi S, Noji S, Kondoh $\mathrm{H}$, Hamada H 1998 lefty-1 is required for left-right determination as a regulator of lefty-2 and nodal. Cell 94:287-297

36. Tessari A, Pietrobon M, Notte A, Cifelli G, Gage PJ, Schneider MD, Lembo G, Campione M 2008 Myocardial Pitx2 differentially regulates the left atrial identity and ventricular asymmetric remodeling programs. Circ Res 102:813-822 